\title{
Childhood-onset autosomal recessive myopathy with external ophthalmoplegia
}

INSERM

\section{Source}

INSERM. (1999). Orphanet: an online rare disease and orphan drug data base. Childhoodonset autosomal recessive myopathy with external ophthalmoplegia. ORPHA:363677

A rare, genetic, non-dystrophic myopathy disease characterized by childhood-onset severe external ophthalmoplegia, typically without ptosis, associated with mild, very slowly progressive muscular weakness and atrophy, involving the facial, neck flexor and limb (upper > lower, proximal > distal) muscles. Muscle biopsy shows type 1 fiber uniformity, absent, or abnormally small, type 2A fibers, increased variability of fiber size, internalized nuclei and/or fatty infiltration. 